\title{
Operational strategies to improve paste plant performance
}

\author{
J Palmer Outotec Pty Ltd, Australia
}

\begin{abstract}
Surface deposition of paste is a recognised tailings management practise, yet some sites operate with beach angles lower than expected due to inconsistent thickener underflow densities. By analysing the issues that limit paste plant performance at several sites, we can develop new operational strategies to achieve better control of the paste properties.

Variability in ore mined leads to changes in settling performance and control systems need to adapt to the changes in flocculation. Where the thickening equipment performance is tightly sized, there can be challenges in maintaining the optimum paste consistency.

Alternative flow sheet solutions are evaluated to achieve improved consistency of thickener discharge and slurry rheology, with the aim of producing more consistent beach angles over the life of the tailings storage facility.
\end{abstract}

Keywords: paste thickening, thickener automation

\section{Introduction}

Thickening, or sedimentation, is a process where a slurry or solid-liquid mixture is separated into a dense slurry containing most of the solids and an overflow of essentially clear water. The driving force for the separation is the gravitational force where the differences in phase densities define the rate of separation of the phases.

The degree of separation achievable with sedimentation is affected by the particle size, shape, surface chemistry and solids density. These variables affect the settling rate in thickeners, which describes the rate of solids settling in the slurry. The designed supernatant flow divided by the settling rate gives the thickener area required. The variables also have an impact on the time required for separation or dewatering in the bed and this influences the compression depth.

By linking smaller particles together, flocculants act to increase the apparent particle size, thus increasing the settling rate. To optimise the effectiveness of flocculants, improvements in thickener feedwell design have been made that have resulted in thickener settling rates increasing greatly. However, these designs are quite mature and only incremental improvements have been achieved recently.

Increasing the depth of thickeners has been the path of development in the search for higher degrees of separation to be achieved. Raking mechanisms are used to apply shear in the compression zone and move the thickened solids to the discharge point. As higher concentrations are achieved in the thickener underflow, the yield stress increases, thus requiring higher raking torques and often heavier rake mechanisms, with the inclusion of pickets. Underflows at high densities are typically described as a paste thickened and typically have plastic-like behaviour with yield stress being the best descriptor.

Paste plants in which high-density underflows are produced are an evolution of conventional tailings disposal systems. While much about the paste thickeners has evolved, the process flow sheet design has not changed significantly. The flow sheet for a traditional paste plant typically has all waste streams from the mineral processing plant consolidated into a single point prior to thickening. This consolidated flow is then split between the thickeners in use. Flocculant and dilution water are added prior to or in the feedwell of each thickener. The separation of solid from liquid occurs in the body of the thickener, at which point the overflow is returned to the plant process water system and the underflow is transported to the tailings storage facility. 
In a traditional model, the thickener is generally located close to the mill and transport of tailings streams is relatively simple. The thickener is designed to operate at a specified underflow density with a given mass of tails fed to the thickener.

When shifting to a paste plant, the objective of the plant can vary slightly from that of a traditional thickening plant. When water recovery is the secondary objective and where the properties of the paste become the defining parameter, it may be worthwhile to look at which material properties are detrimental to the paste behaviour.

Each plant design should carefully consider which variables are limiting the plant performance. While flocculation and yield stress are the major factors in thickener design, in this paper we have considered automation and control, together with the implications of yield stress variability, tailings beach angle and pumpability as the limiting factors from a plant perspective.

\section{Plant definition, control and rate limiting variables}

For the purpose of this paper, we are defining a paste plant (Figure 1) as a thickener, pumping system and the necessary ancillaries required to operate the plant. As all of the components are interactive, it is necessary to look at the whole system rather than just the thickener to optimise the performance. Due to the high frictional losses $(2-8 \mathrm{kPa} / \mathrm{m})$ required to pump paste to the final deposition point, a paste plant is becoming a self-contained plant located remotely from the main processing facility.

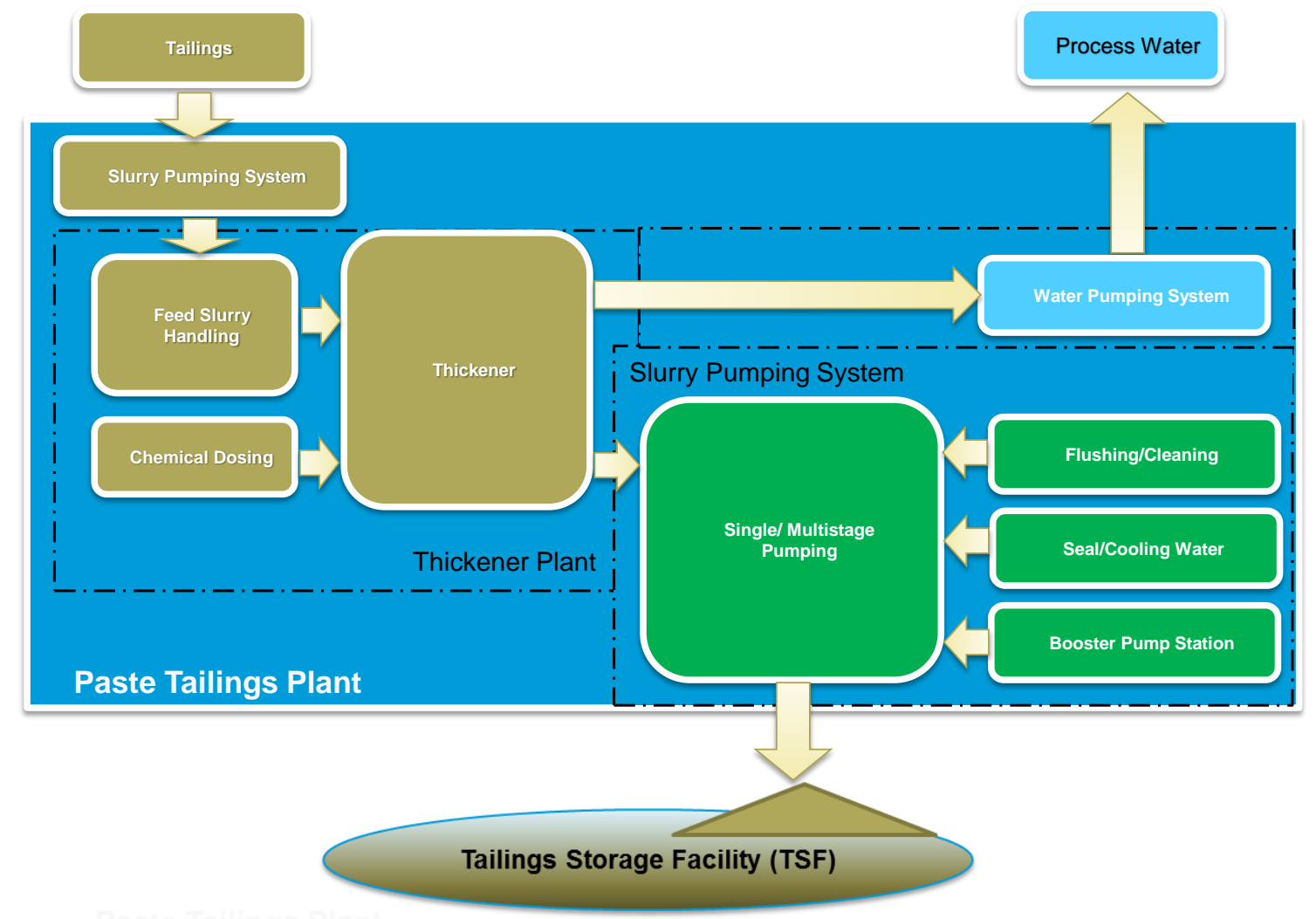

Figure 1 Generic flow sheet 


\subsection{Rate-limiting variables}

To improve the performance of a paste plant, it is best to look at the variables within the plant that limit the performance of the plant. While prediction of plant performance is useful, a better approach is to look at areas where paste production can be improved. Ultimately, the purpose of a paste plant is to recover water from the tailings and to produce a paste that best suits the disposal strategy.

\subsection{Control}

Although the duty of a thickener can be defined in quite simple terms, the thickener will experience a wide range of operational conditions throughout its life. Mass flow of solids varies with milling rates, the concentration of solids in the feed varies with operational issues and the ore treated in the mill changes with the geology of the mine.

This variability in operation results in changes in yield stress of the thickened tailings and can have negative impacts on the tailings deposit beach slope or pumpability of the tailings. Yield stress is not commonly measured online and underflow density has been taken as a de facto measure of yield stress in many studies. The variability in operation has been noted by many sites, and the implication of underflow density has been commented on by Seddon and Fitton (2011) and later by Behnam et al. (2017). Both papers indicated that the design underflow solids concentrations for high-rate and paste thickeners are generally achieved on a time average basis, but a lot of the time thickeners have underperformed. Typically, thickener performance is not constant and the behaviour of the thickened tailings at the point of deposition can vary considerably. While the variability is less with paste thickeners, the variability can have a significant impact on the slurry transport properties and the beach slope at the tailings storage facility.

Behnam et al. (2017) noted that the variability of thickener underflow density is significantly lower than the variability of the mass flow to thickeners. This indicates that while thickeners need to be adequately sized to meet the operational requirements of a plant, oversizing thickeners may not compensate for underflow variability. For thickeners to achieve consistent underflow density, they should be operated below their limits or have better control systems that enable operation closer to the design requirement.

The variability of thickener underflow density in operation has been described as a normal distribution through to asymmetrical two-tailed distribution. Behnam et al. (2017) recommended a coefficient of variation (CV) of 0.05 for high-rate thickeners (HRTs) and 0.03 for paste thickeners. This variability can be attributed to operator set-point adjustment, control system function, variability in throughput, operational changes in point of discharge and changes in slurry properties.

It is expected that the distribution for conventional and HRTs, where there are less constraints on the achievable density, will behave more like a normal distribution. High-density and paste thickeners, which operate at close to the limits of thickening, will have the distribution truncated at the upper limits by underflow yield stress or slurry transport limits, resulting in asymmetrical distributions with a fat tail. Data from a high-rate thickener in an alternative site (Figure 2) with good instrumentation and conventional controls demonstrates similar behaviour to that described by Seddon and Fitton (2011). The distribution is close to normal with a CV of 0.05 as shown in Figure 3. 


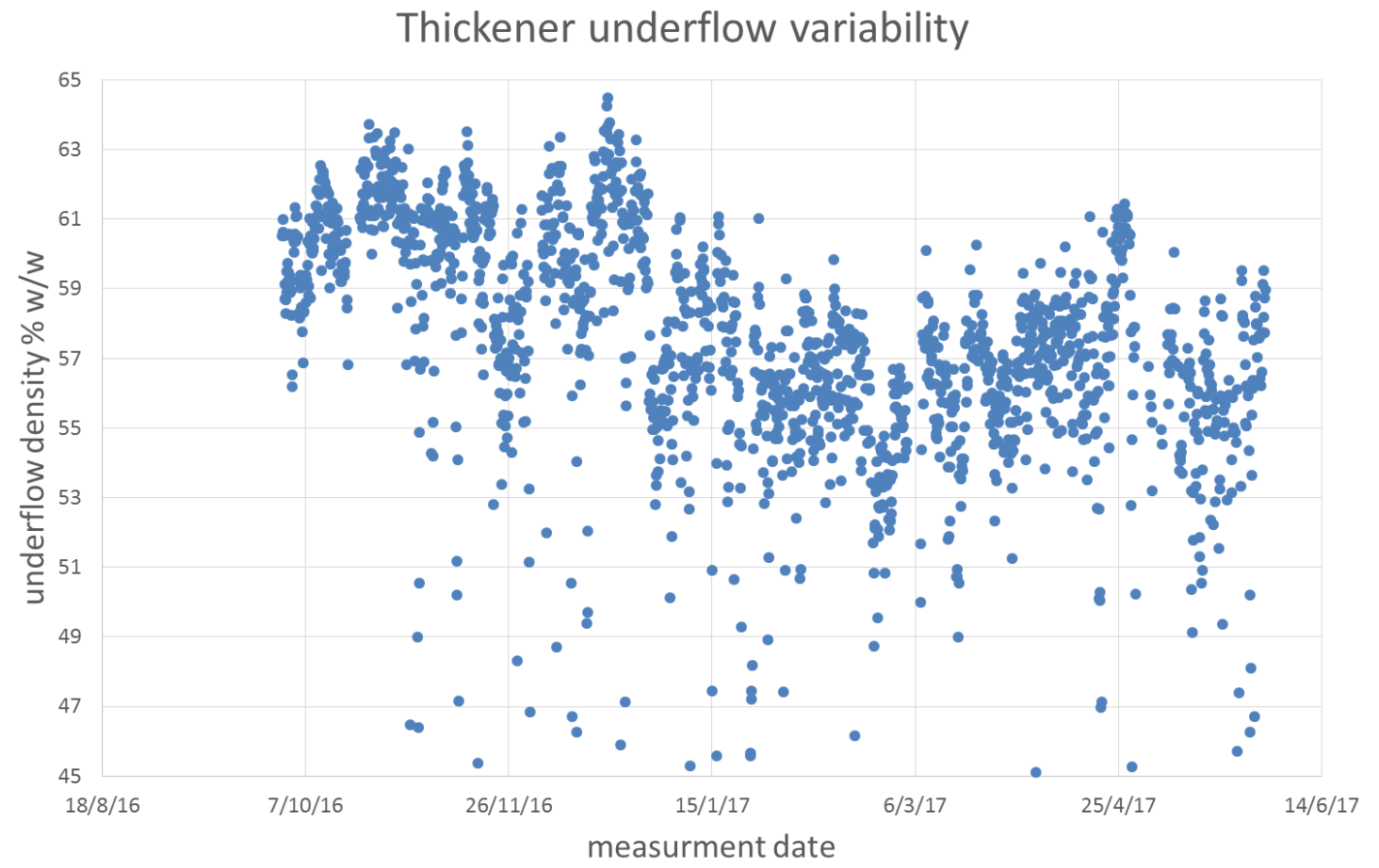

Figure 2 Density results over measurement period

\section{Underflow density distribution}

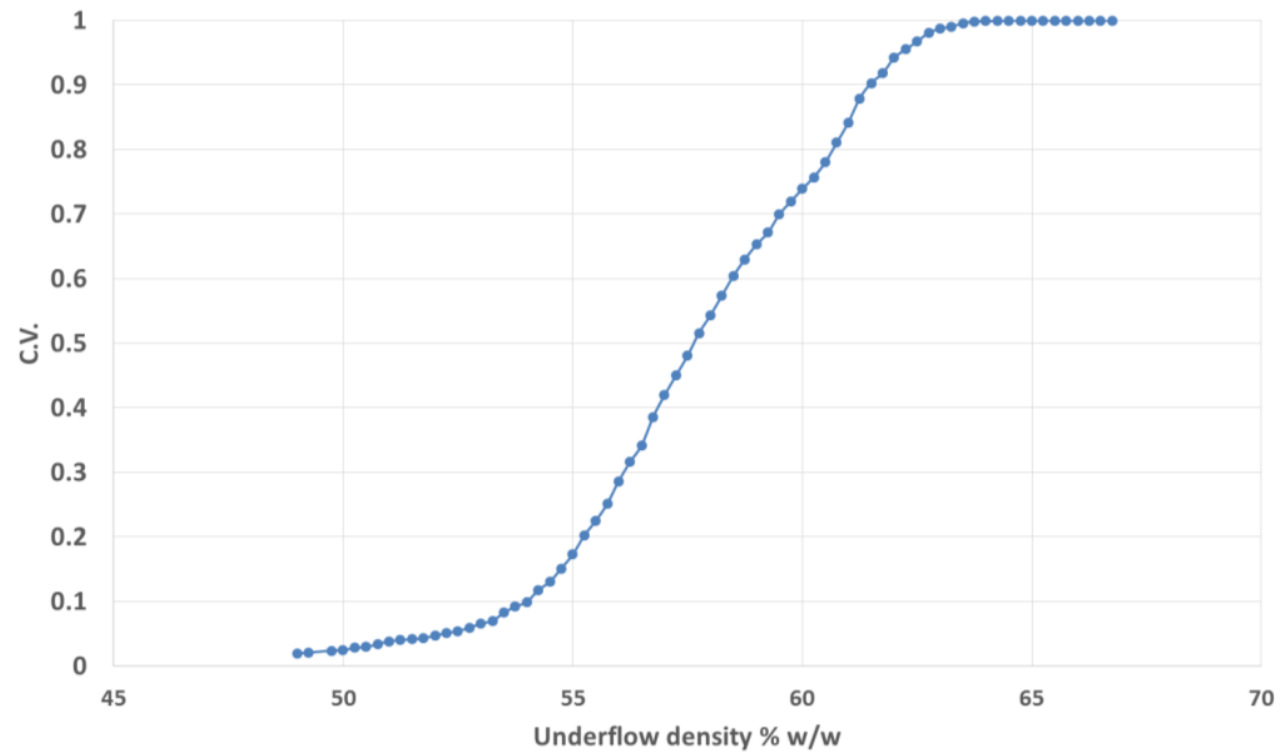

Figure 3 Distribution of density

Kosonen et al. (2017) have shown that by improving control systems and utilising multivariable model predictive control platforms to replace single loop proportional integral control, thickeners can operate with significantly tighter distribution of underflow density and reduced operation variability. With improvements in control logic, the upper limit of achieved density is quite constant. However, the average increases and the $\mathrm{CV}$ is reduced to less than 0.02 in the example case. The data (Figure 4) shows a before implementation reference green curve of slurry density with a long tail on the low-density distribution against an after implementation (validation) curve in red with a tight distribution of density distribution.

While improved automation is key to achieving improvements in underflow density, these optimisations cannot be achieved without good instrumentation to support the control system. 
Relative distribution of underflow density

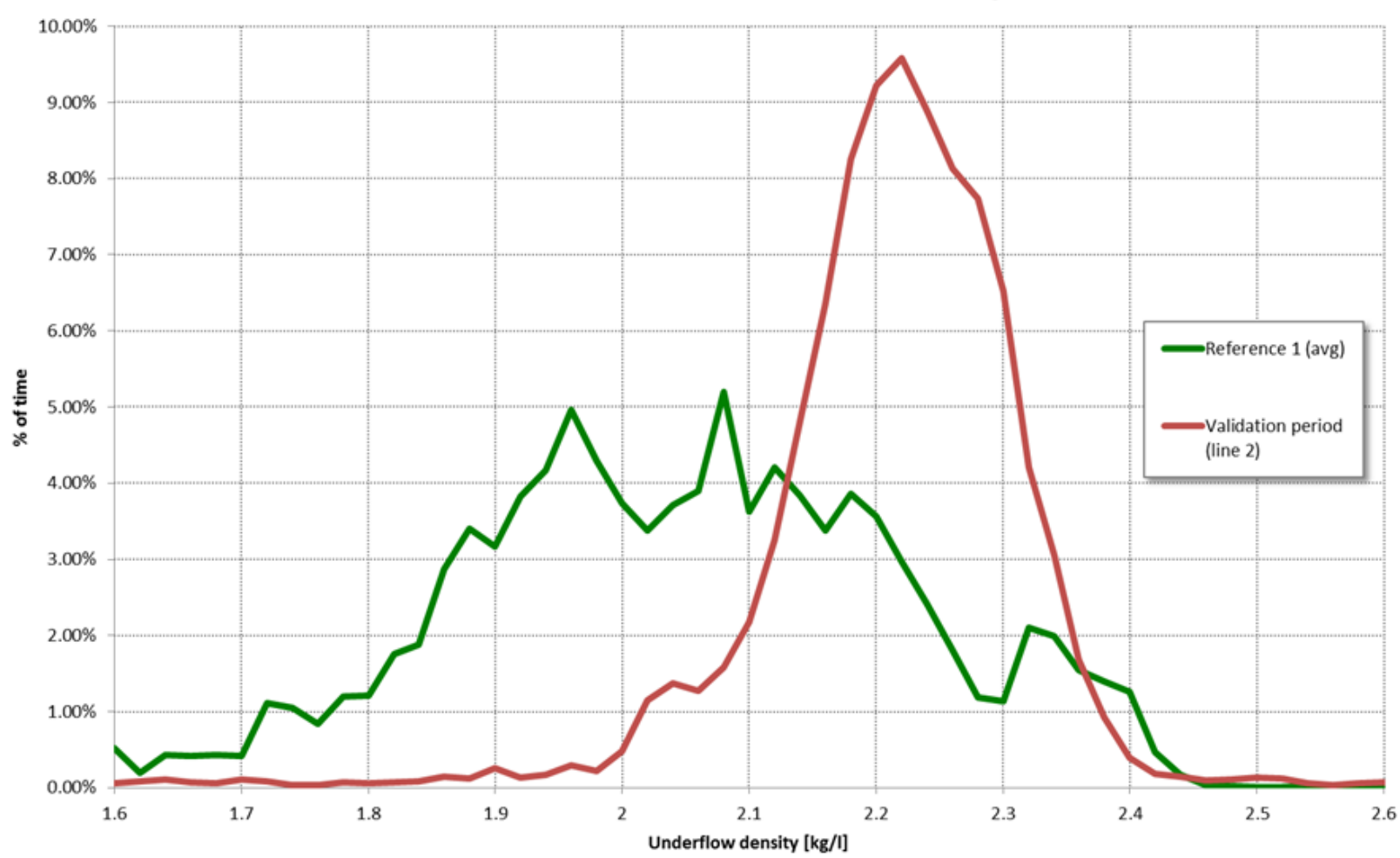

Figure 4 Comparison of underflow density (Kosonen et al. 2017)

Further examples (Figure 5) of a paste plant operating with an advance control system show consistent underflow density. During operation, despite the constant underflow density, small adjustments in dilution water are required to manage a consistent paste pumping pressure. At the reference site, beach angles consistent with pilot testing have been achieved in full-scale production. During operation, the distribution of underflow density is close to normal, with a CV of less than 0.01 .

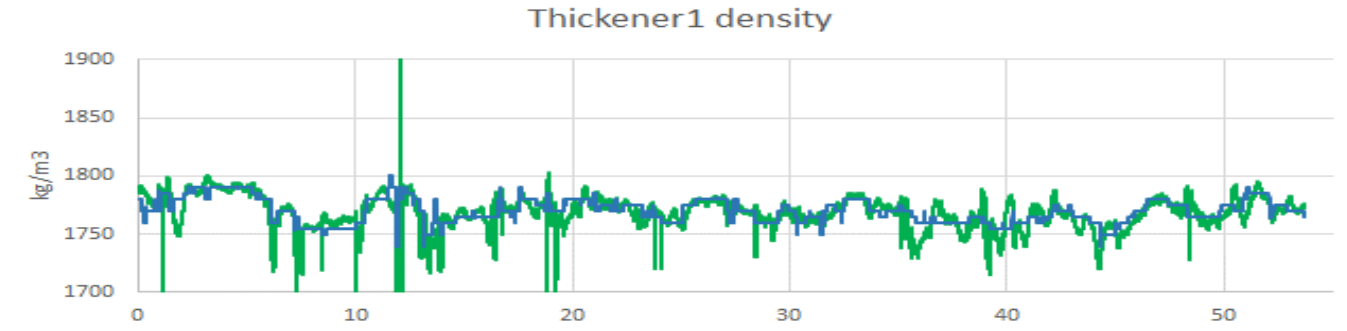

(a)

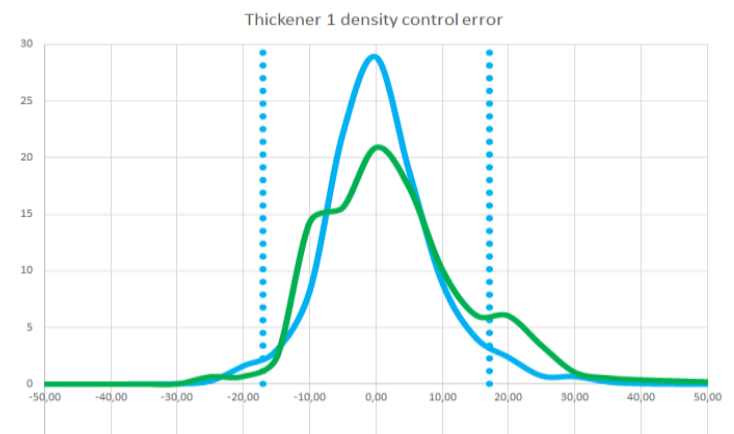

(b)

Figure 5 Density within $\pm 17 \mathrm{~kg} / \mathrm{m}^{3}$ from the set-point $95 \%$ of time; (a) Underflow density histogram; and, (b) Thickener optimiser, control on; green - May 2017, blue - July-August 2017 
One important factor in paste plant performance variability is the impact of plant operators. Decisions made in milling and operational behaviour can have significant impact on the quantity and properties of the tailings, and these variations flow through the process to the paste plant generally without notice. Paste plant operators may be faced with significant variability in feed to a plant that is best suited to constant steady-state operation. As noted earlier, the implications of set-point changes can have significant effects on the paste plant output with long lags between action and consequence. The adjustable variables have complex interactions that are generally poorly understood and the skills of a plant operator can significantly impact on the paste plant performance.

Despite the improvements in instrumentation and automation, some paste plants still fail to achieve design performance. With these factors in mind, there is anecdotal evidence that good operator training and moderate transition periods between the plant suppliers and the operation team leads to better long-term plant stability and accelerates the ramp-up from commissioning to full-scale design performance.

\subsection{Beach angle}

Thickened paste plants recover water and produce paste with a high density. Each parameter will have a desired characteristic, and usually one of these two objectives is dominant or rate limiting. While water recovery is optimised by maximising paste density in plants where the tailings storage facility disposal is the dominant objective, there may be a limit to the paste properties such as pumping pressure, and conventional control systems are less well suited to optimising the paste characteristics.

With paste disposal of tailings, the beach angle plays an important factor in storage volumes and in dam safety, yet the control parameters in a thickener are underflow density, rake torque and flocculant dosing rate. Wates et al. (2015) give good correlations between tailings yield stress and beach angle achieved, indicating that yield stress is a good indicator of deposition. Yield stress is not a typical control parameter or online measured variable.

Plots of underflow density against yield stress are routinely produced from site data, yet the accumulated field data shows a significant scattering of results from production units. This tends to indicate that with changes in ore type, particle size distribution and flocculant dosing, the inter-particle forces are not directly related to percent solids. The slurry variability between underflow density and yield stress may help to account for some of the variability in slurry density displayed by thickener operational data.

Instrumentation that can directly measure yield stress online may represent a better control parameter than underflow density for the accurate control of paste thickeners used for high-angle beach deposition of tailings.

Even the best instrumentation and control systems cannot alter the behaviour of the slurry, and systems that must thicken all the material fed to the system will be restricted in achievable beach angle and beach concavity.

\subsection{Flow sheet alternatives}

Paste systems in the backfill applications control the particle size distribution and solids concentration of the paste to optimise the amount of binder required to maintain strength of fill.

Paste systems that incorporate desliming and alternative disposal points for fines or systems that add additional coarse fraction may be able to achieve better disposal outcomes than systems that treat whole tailings. McPhail (2015) proposed several alternatives for classification, alternative dewatering and recombination as a mechanism to increase paste density. In practice, few of these options are applied in industry. This may be in part because the recombination changes the method of dewatering but does not alter the paste properties. Where a slurry has components that are detrimental to the paste properties, those components should be removed for alternative disposal. 
A good example of this is the situation where coarse, fast-settling material is included in a slurry stream. While it may appear that this material enhances settling, it can add instability to the paste thickener operation. This instability is created by a substantial increase in the yield stress and asymmetrical deposition in the thickener.

Multiphase computational fluid dynamics modelling with a simulated rotating rake can help predict the rake torque stability and the possibility of rat-holing or donuts. However, the consequences of adapting the thickener to accommodate all material can be a huge increase in rake torque or heavy bracing to counter tipping loads. A more effective solution (Figure 6) can be to add a scalping stage with a vibrating screen before the thickener to remove oversize (>300 um). Dewatering screens can achieve $75 \% \mathrm{w} / \mathrm{w}$ on the removed oversize which is self-draining and can be transferred to the dam wall or a dry stack disposal with minimal impact to the overall paste system water recovery.

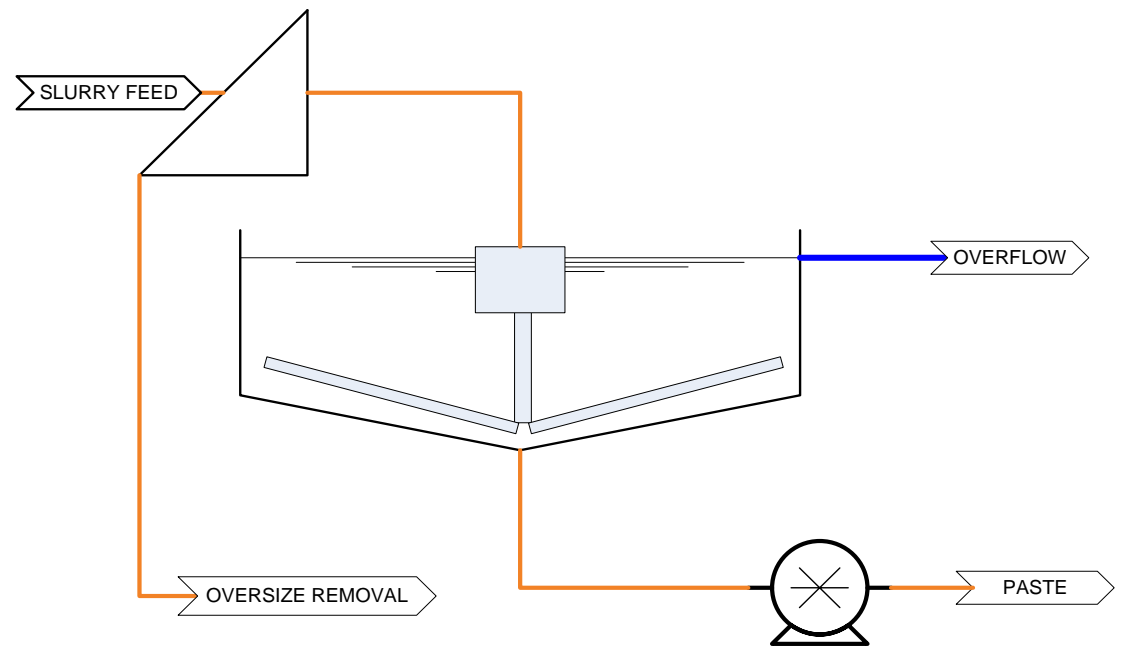

SCALPING DUTY

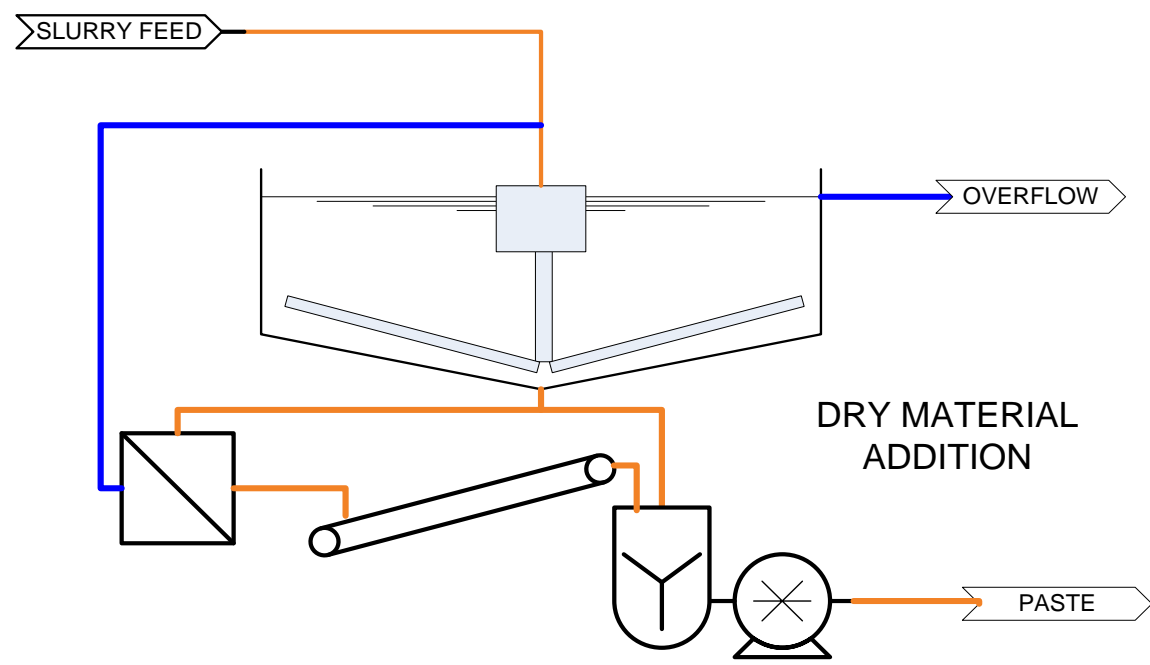

Figure 6 Alternative flow sheets 
At the extreme limit when the deposition strategy requires the paste thickening to achieve a high-density underflow with a very high yield stress material, the cost of paste thickening escalates and the operability may become unreliable. In these cases, a more controllable and cost-effective solution (Figure 6) may be to target a lower thickener underflow density and add dry material to adjust the paste density to the required level. While this strategy requires a mixing unit prior to pumping or transportation, the savings in thickener construction may offset the cost of the additional mixing and dewatering stage. The dry material can be sourced from borrowed material, reclaimed dry tailings or by filtration of part of the tailings stream.

\subsection{Pumping}

The pumping or transport of paste can require high pressures and involve expensive infrastructure to transfer the paste even moderate distances. Generally, low-velocity laminar flow conditions are possible in paste pipelines, and pipeline friction pressure gradient losses will be in excess of $1.5 \mathrm{kPa} / \mathrm{m}$ and operating pressure gradients between 2 and $10 \mathrm{kPa} / \mathrm{m}$ are commonly observed.

With the high-friction pressure losses, energy balances for paste thickening systems are quite different than conventional thickening solutions. The high pressures required to pump paste indicate that paste thickeners should be located close to the deposition point in contrast to conventional thickening systems where the thickening is located close to the concentrator. In cases with long pumping distances, low-density processing, or large elevation differences, two-stage thickening may be required. Figure 7 indicates alternative systems.

Two-stage thickening consists of different types of thickener as defined by the duty. Stage one thickening is required to increase density to an optimum level for transport, and stage two thickening is designed to optimise tailings storage facility deposition.

The increase in capital of a more complex thickening system needs to be compensated by a reduction energy and reduced pumping, piping and tailings storage facility infrastructure costs.

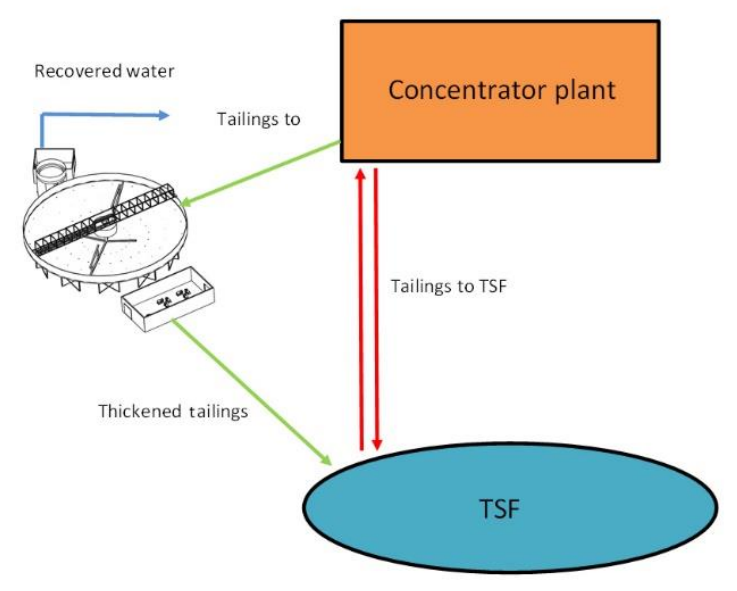

(a)

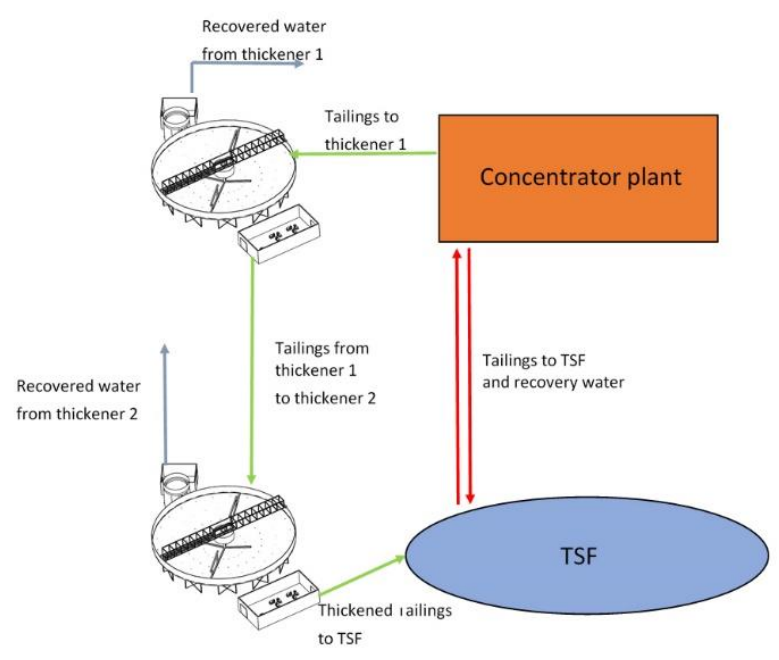

(b)

Figure 7 Alternative flow sheets; (a) One-stage thickening; and, (b) Two-stage thickening

\section{Water quality}

Paste plants are often selected to improve water recovery and have been effective in reducing water consumption in many plants. This improvement in water recovery results in greater recycling of water within the processing plant. As show in Figure 8, the water recovered is used throughout the processing plant. The fresh water usage is reduced to the range of $0.4-0.7 \mathrm{~m}^{3} / \mathrm{hr}$, assuming that no bleed is recovered from the tailings storage facility. 


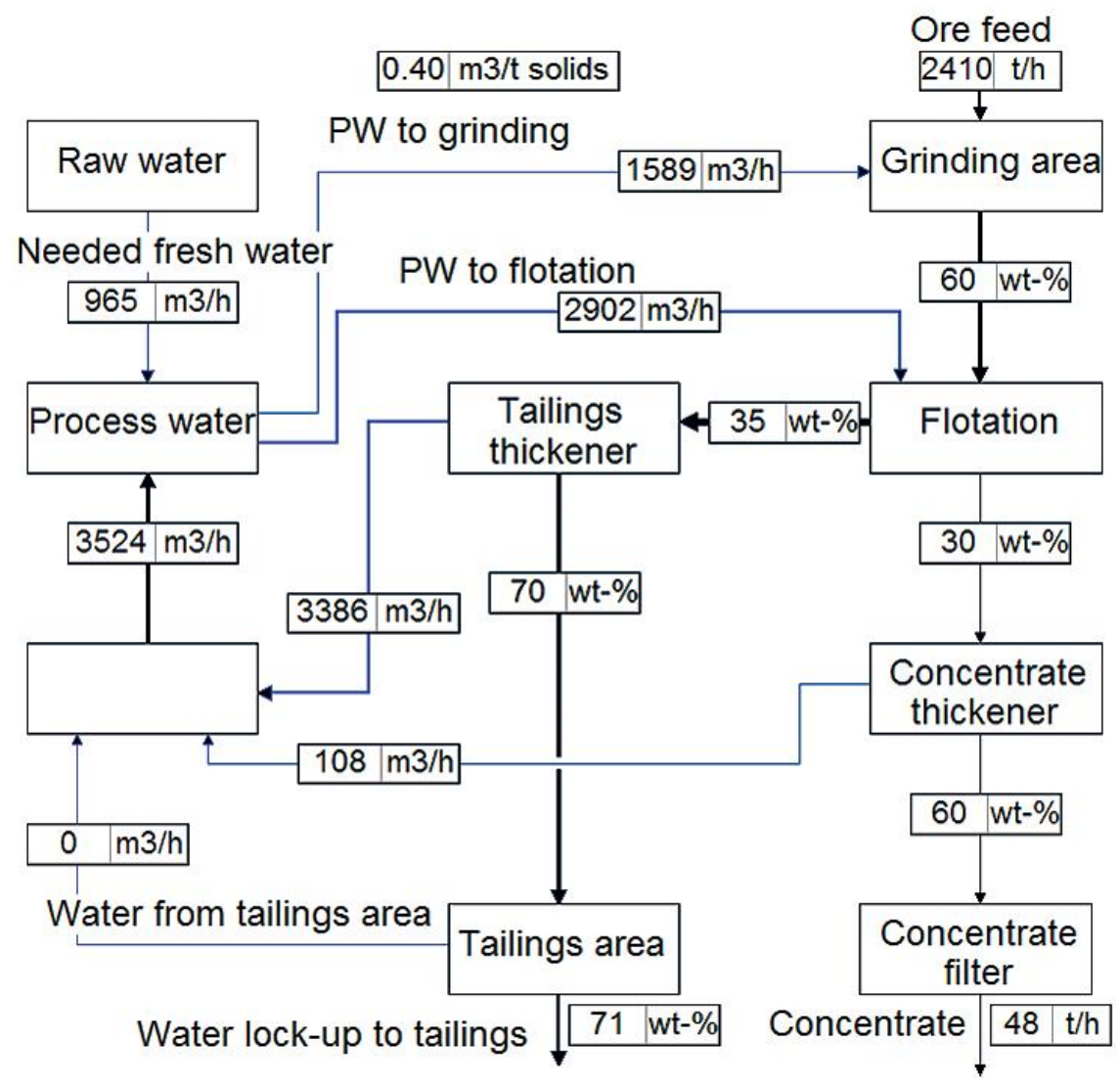

Figure 8 Typical flotation plant water circuit for paste thickening (Jansson et al. 2014)

One consequence of the improved water recovery is the concentration of salts and chemicals utilised in the plant processing. The implication of this concentration varies considerably from process to process, but it can lead to process disturbances and may require the inclusion of a water treatment system in the paste plant. Paste deposition with beach deposition and minimal bleed represents an improvement in water quality compared to water recovered from a tailings storage facility where evaporation and exposure to the elements can significantly increase salinity and alter the water chemistry. Schumann et al. (2009) noted that recycled process water can adversely affect flotation performance, and concluded that while general collectors are removed through either adsorption or degradation, other collectors may be relatively stable and are likely to be present in short-recycle water recovered from thickeners in contrast to water recovered from the tailings storage facility which has a much longer recycle.

\section{Conclusion}

The reliable production of paste is dependent upon more than just the thickener. In order to optimise the paste production, it is necessary to ensure that the infrastructure supporting the thickener is also designed for the duty.

Plant control is an area where significant improvement in thickener performance can be enhanced, stabilising the yield stress in the thickened underflow and improving the average density achieved. The reported distribution of underflow density corresponds well to other production thickeners and a CV of 0.05 for HRT and 0.03 for paste thickeners can be expected with conventional control systems. Installing more-advanced control systems based on multivariable model predictive control (MPC) paste plants can operate with density variability to the range of a CV of 0.02 for HRT and 0.01 for paste thickeners.

Paste systems are controlled by measurable parameters, and in projects where beach angle optimisation is the primary objective, current technologies are limited. Improvements in instrumentation could lead to better tailings storage facility management. 
Improvements in a paste plant may be achieved by adjusting the plant flow sheet to suit the overall system objectives. Significant energy savings can be realised by optimising the paste plant location. Thickening all of the tailings can introduce undesirable components, and treating the stream to remove these undesirable components may lead to improved plant stability and reduced costs.

With improved recovery of water, the plant water circuit is more closed and water quality can suffer resulting in the need for water treatment. The implication of water quality should be evaluated when considering paste thickening solutions.

\section{References}

Behnam, P, Sadegh, J \& Seddon KD 2017, 'Thickener performance variability: underflow soils concentration and flowrate', Proceedings of the 20th International Seminar on Paste and Thickened Tailings, University of Science and Technology Beijing, Beijing, pp. 29-40.

Jansson, K, Kauppi, J \& Kotiranta, T 2014, 'Towards minimum impact Cu concentrator - a conceptual study', Materia, vol. 4, pp. 64-67.

Kosonen, M, Kauvosaari, S, Gao, S \& Henrikson, B 2017, 'Performance optimisation of paste thickening', Proceedings of the 20th International Seminar on Paste and Thickened Tailings, University of Science and Technology Beijing, Beijing, pp. 13-22.

McPhail, GI 2015, 'Thickening plant concepts', in RJ Jewell and AB Fourie (eds), Paste and Thickened Tailings - A Guide, 3rd edn, Australian Centre for Geomechanics, Perth, p. 164.

Schumann, R, Levay, G \& Ametov, I 2009, 'The impact of recycling on process water quality in mineral processing', Proceedings of the Water in Mining Conference, The Australasian Institute of Mining and Metallurgy, Melbourne, pp. 79-86.

Seddon, KD \& Fitton, TG 2011, 'Realistic beach slope prediction and design', in RJ Jewell and AB Fourie (eds), Proceedings of the 14th International Seminar on Paste and Thickened Tailings, Australian Centre for Geomechanics, Perth, pp. 281-293.

Wates, JA, Venter, HA, Dittle, VT \& Cooper, RA 2015, 'Practical observations in beach slope formation and application of the thin layer equilibrium model to observed data', in RJ Jewell and AB Fourie (eds), Proceedings of the 18th International Seminar on Paste and Thickened Tailings, Australian Centre for Geomechanics, Perth, pp. 443-453. 